\title{
Counteranion-Stabilized Titanium(IV) Isopolyoxocationic Clusters Isolated from Water
}

\author{
Guanyun Zhang, Jie Hou, Mingzhong Li, Chen-Ho Tung and Yifeng Wang*
}

Key Laboratory for Colloid and Interface Chemistry of Ministry of Education, School of Chemistry and Chemical Engineering, Shandong University, Ji'Nan 250199, P. R. China

\section{Table of Contents}

Figure S1. TGA analysis of $\mathbf{T i}_{6} \mathbf{B}$

Figure S2. Powder XRD pattern of $\mathbf{T i}_{6} \mathbf{C}$

Figure S3. Powder XRD pattern of $\mathbf{T i}_{6} \mathbf{B}$

Figure S4. Powder XRD pattern of $\mathbf{T i}_{\mathbf{8}} \mathbf{I}$

Table S1. BVS calculations

Table S2. Selected bond parameters

Figure S5. Illustration showing stabilization of $\left\{\left[\mathrm{Ti}_{6}\left(\mathrm{O}_{\mu}\right)_{8}\left(\mathrm{O}_{t} \mathrm{H}_{2}\right)_{20}\right] \mathrm{Cl}_{14}\left(\mathrm{OH}_{2}\right)_{4}\right\}^{6-}$ by TBA cation

Figure S6. IR spectra

ATR-FTIR and Raman analysis

Table S3. The values used for calculating $v_{1} / v_{2}$

Table S4. Vibrational band shift calculations

Figure S7. Raman spectra of $\mathbf{T i}_{\mathbf{6}}$ compounds

Figure S8. IR spectra of $\mathbf{T i}_{8} \mathbf{C}$ and $\mathbf{T i}_{8} \mathbf{C}-\boldsymbol{d}$.

Table S5. IR band of $\mathbf{T i}_{8}$ clusters

Table S6. Tis's IR band shift due to deuterium-labeling

Figure S9. Raman spectra of $\mathbf{T i}_{8}$ compounds

Figure S10. FTIR spectra of $\mathbf{T i}_{6} \mathbf{B}$ in solid form and in acetonitrile solutions

Figure S11. UV-vis absorption spectra of $\mathbf{T i}_{6} \mathbf{C}$ in acetonitrile

Figure S12. ${ }^{1} \mathrm{H}$ MAS NMR of $\mathbf{T i}_{8} \mathbf{C}$

Figure S13. ${ }^{1} \mathrm{H}$ NMR spectra of $\mathbf{T i}_{\mathbf{6}} \mathbf{C}$ in acetonitrile at 25 and $-40{ }^{\circ} \mathbf{C}$

Figure S14. ${ }^{35} \mathrm{Cl}$ NMR of $\mathbf{T i}_{\mathbf{6}} \mathbf{C}(0.10 \mathrm{M}$; black) and TBAC (1.4 M; blue) in acetonitrile solutions A brief description on DFT calculations

Figure S15. Optimized $\mathbf{T i}_{\mathbf{6}}$ and $\mathbf{T} \mathbf{i}_{8}$ cluster structures using DFT method

Figure S16. Optimized $\mathbf{T i}_{\mathbf{6}}$ cluster structure without counter-anions using DFT method 


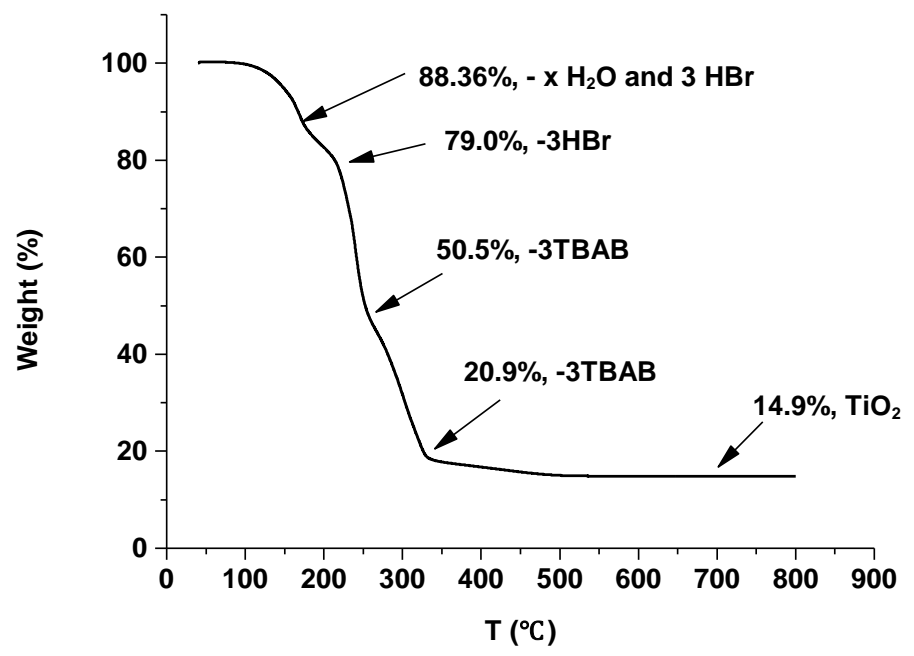

Figure S1. TGA analysis of $\mathbf{T i}_{\mathbf{6}} \mathbf{B}$ and possible assignments for loss of weight.

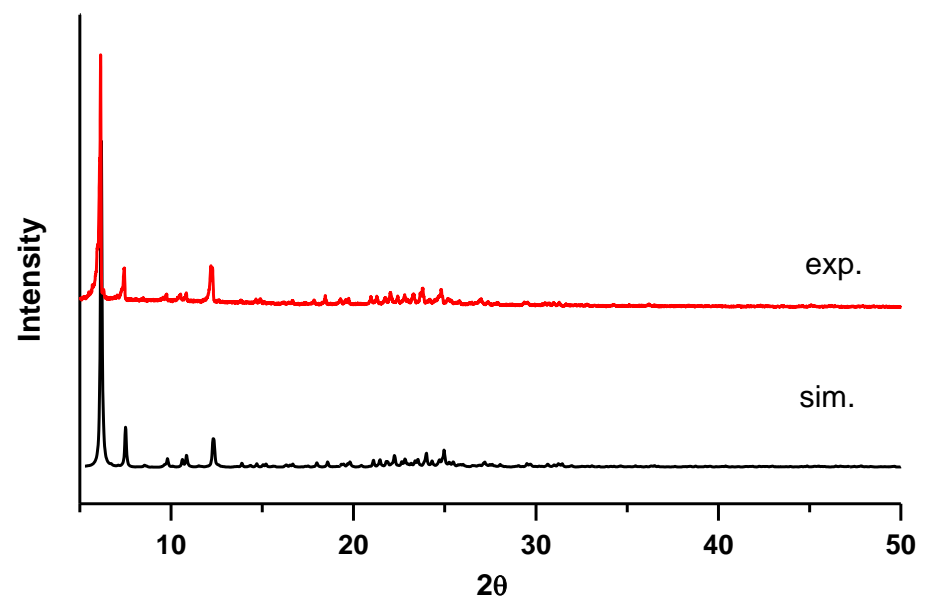

Figure S2. Powder XRD pattern of $\mathbf{T i}_{6} \mathbf{C}$.

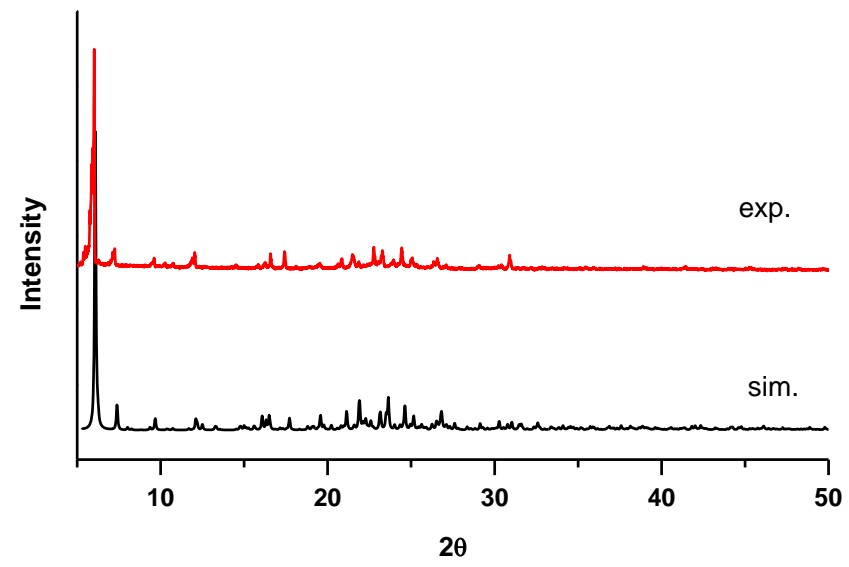

Figure S3. Powder XRD pattern of $\mathbf{T i}_{\mathbf{6}} \mathbf{B}$. 


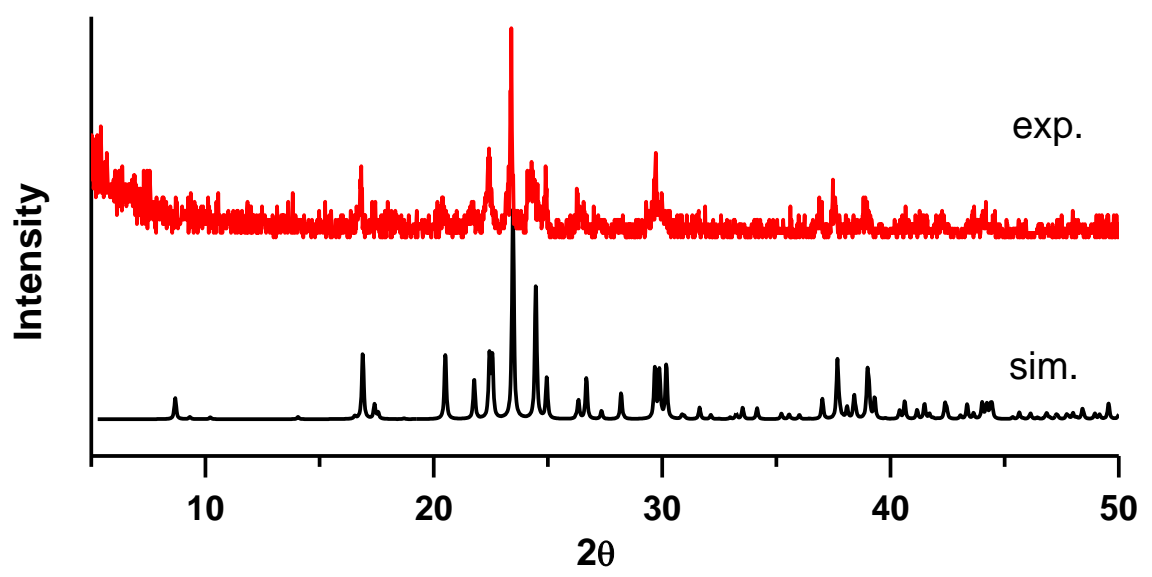

Figure S4. Powder XRD pattern of $\mathbf{T i}_{\mathbf{8}} \mathbf{I}$.

Table S1. BVS calculations for O1-O7 atoms in $\mathbf{T i}_{6} \mathbf{B}^{\mathbf{a b c}}$

\begin{tabular}{|l|l|l|l|}
\hline Atom & Atom & Distance & BVS \\
\hline $\mathrm{O}\left(\mathrm{H}_{2}\right) 1$ & Ti2 & 2.113 & 0.447 \\
\hline $\mathrm{O}\left(\mathrm{H}_{2}\right) 2$ & Ti2 & 2.059 & 0.517 \\
\hline \multirow{\mathrm{O}3}{}{} & Ti1 & 1.865 & 0.874 \\
\cline { 2 - 4 } & Ti2 & 1.750 & 1.192 \\
\hline Total & Ti1 & 2.135 & 2.066 \\
\hline $\mathrm{O}\left(\mathrm{H}_{2}\right) 4$ & Ti1 & 2.111 & 0.421 \\
\hline $\mathrm{O}\left(\mathrm{H}_{2}\right) 5$ & Ti1 & 2.147 & 0.449 \\
\hline $\mathrm{O}\left(\mathrm{H}_{2}\right) 6$ & Ti1 & 1.794 & 1.408 \\
\hline & Ti1' & 1.810 & 1.058 \\
\hline Ootal & & & 2.116 \\
\hline
\end{tabular}

${ }^{\mathrm{a}} \mathrm{BVS}$ calculations were performed using Bond Valence Calculator (Version 2.0, February 1993). ${ }^{\mathrm{b}}$ Default parameters provided by Bond Valence Calculator are used, i.e., $R_{0}=1.815$ and $B=0.370 .{ }^{\circ}$ the labels with prime (') are for nearest symmetry-identical atoms.

Table S2. Selected bond parameters for $\mathrm{Ti}_{6} \mathrm{~B}, \mathrm{Ti}_{6} \mathrm{C}$ and $\mathrm{Ti}_{8} \mathrm{I}^{\text {ab }}$

\begin{tabular}{|c|c|c|c|c|c|}
\hline $\mathbf{T i}_{\mathbf{6}} \mathbf{B}$ & & $\mathbf{T i}_{6} \mathbf{C}$ & & $\mathbf{T i}_{8} \mathbf{I}$ & \\
\hline \multicolumn{6}{|c|}{ Ti-O Bond Lengths, $\AA$} \\
\hline $\mathrm{Ti}-\mathrm{O}_{t}$ & $2.154-2.036$ & $\mathrm{Ti}^{-} \mathrm{O}_{t}$ & $2.178-2.061$ & $\mathrm{Ti}^{-} \mathrm{O}_{t}$ & $2.161-2.174$ \\
\hline $\mathrm{Ti}-\mathrm{O}_{\mu}$ & $1.864-1.751$ & $\mathrm{Ti}-\mathrm{O}_{\mu}$ & $1.870-1.743$ & $\mathrm{Ti}-\mathrm{O}_{\mu}$ & $1.806-1.812$ \\
\hline \multicolumn{6}{|c|}{ Ti $\cdots$ Ti Separations, $\AA$} \\
\hline Ti1 $\cdots$ Ti2 & 3.542 & Тi1 $\cdots$ Ti4 & 3.553 & Ti1 $\cdots$ Ti1 $^{\prime}$ & 3.517 \\
\hline Til $\cdots$ Til' & 3.522 & Ti2 $\cdots$ Ti5 & 3.533 & Ti2 $\cdots \mathrm{Ti}^{\prime}{ }^{\prime}$ & 3.514 \\
\hline 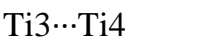 & 3.530 & Ti5 $\cdots$ Ti6 & 3.542 & & \\
\hline \multirow{2}{*}{ 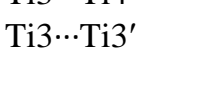 } & 3.528 & Ti3 $\cdots$ Ti6 & 3.546 & & \\
\hline & & Ti8 $\cdots$ Ti9 & 3.524 & & \\
\hline \multicolumn{6}{|c|}{ Ti-O-Ti bond angles, $^{\circ}$} \\
\hline Ti1-O3-Ti2 & 156.9 & Ti1-O22-Ti2 & 154.4 & Ti1-O2-Ti2 & 152.8 \\
\hline Ti1-O7-Ti1' & 155.4 & Ti1-O21-Ti4 & 155.8 & Ti2-O3-Ti2' & 152.0 \\
\hline Ti4-O14-Ti14 & 156.3 & Ti2-O23-Ti3 & 157.4 & & \\
\hline Ti3-O10-Ti4 & 155.4 & Ti2-O24-Ti5 & 156.8 & & \\
\hline
\end{tabular}

${ }^{\text {a }}$ The labels with prime (') are for nearest symmetry-identical atoms. ${ }^{\text {b }}$ The labels which are not shown in Figure 1 refer to the crystallographic information files. 


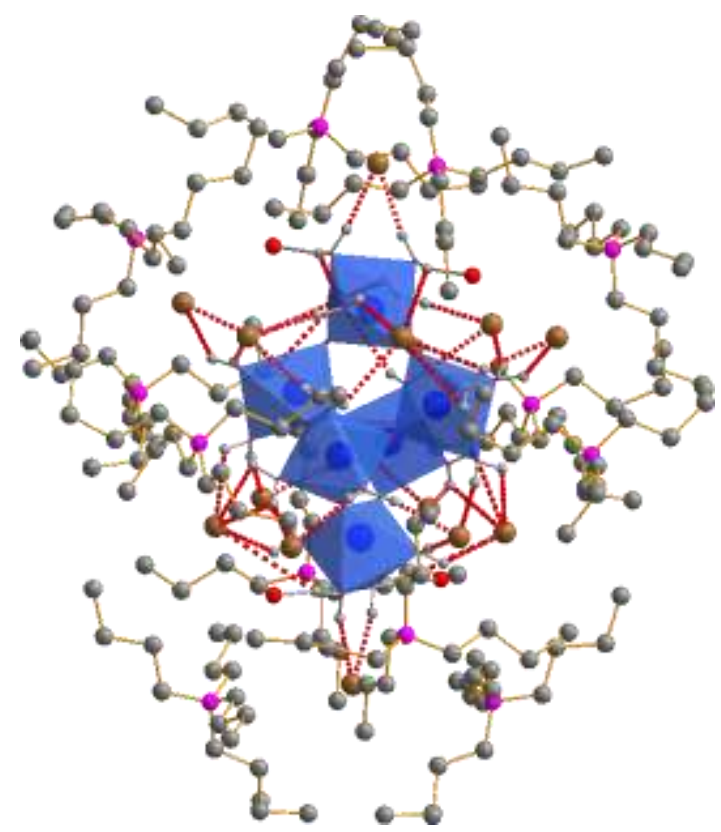

Figure S5. The TBA cations surrounding the $\left\{\left[\mathrm{Ti}_{6}\left(\mathrm{O}_{\mu}\right)_{8}\left(\mathrm{O}_{t} \mathrm{H}_{2}\right)_{20}\right] \mathrm{Br}_{14}\left(\mathrm{OH}_{2}\right)_{4}\right\}^{6-}$ in the crystal structure. Blue, Ti; brown, Br; red, O; grey, C; pink, N; pale, $\mathrm{H}$.

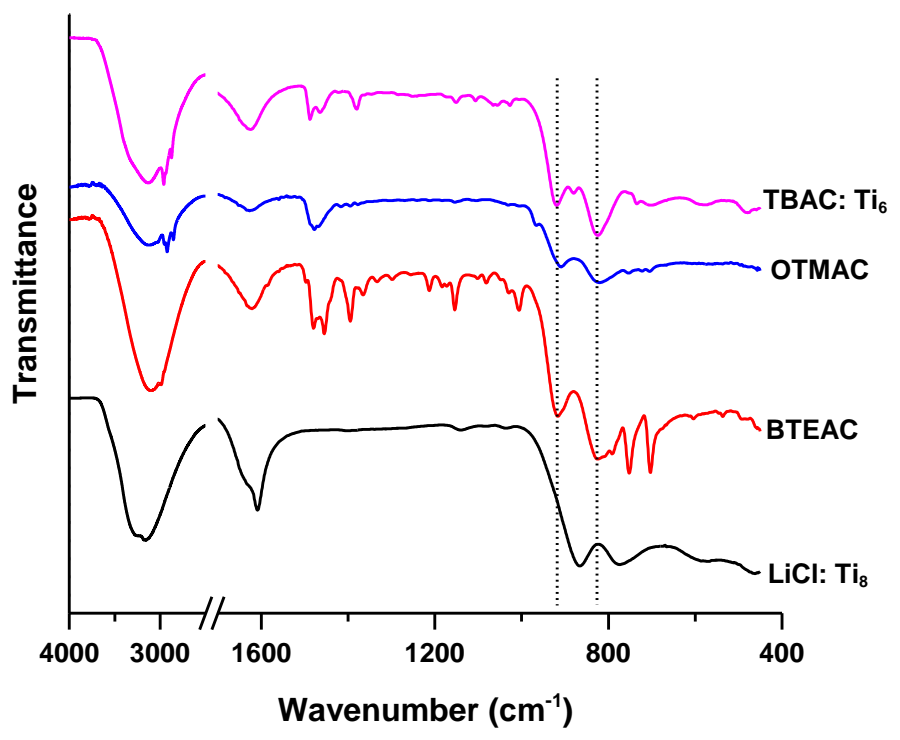

Figure S6. IR spectra of products by reaction of $\mathrm{TiCl}_{4}$ with $\mathrm{TBAC}$, octyltrimethylammonium chloride (OTMAC), benzyltriethylammonium chloride (BTEAC), and $\mathrm{LiCl}$.

\section{ATR-FTIR and Raman analysis}

The stretching frequency of a bond can be approximated by Hooke's Law ${ }^{1,2}$. For this, two atoms and the connecting bond are treated as a simple harmonic oscillator composed of two masses (atoms) joined by a spring. The vibration frequency $(v)$ of the spring is related to its force constant $(K)$ and the reduced 
mass $(\mu)$ of the two atoms by eq 1 ,

$v=\frac{1}{2 \pi c} \sqrt{\frac{K}{\mu}}$

Where, $c$ is velocity of light in vacuum and $\mu=m_{a 1} \cdot m_{a 2} /\left(m_{a 1}+m_{a 2}\right)$.

The ratio of the vibration frequency values of two bonds can be calculated via eq (2). Therefore, band shift arising from isotope labeling or element substitution without structural readjustment can be predicted. This is used as the main method for IR/Raman peak assignment in this article.

$\frac{v_{1}}{v_{2}}=\sqrt{\frac{K_{1} \cdot \mu_{2}}{K_{2} \cdot \mu_{1}}}$

For calculations of $v_{1} / v_{2}$, values of $K$ and are listed in Table S3.

Table S3. The values used for calculating $v_{1} / v_{2}$

\begin{tabular}{llll}
\hline bond & $\mu$ (a.u.) & $K\left(10^{5} \mathrm{dyn} \cdot \mathrm{cm}^{-1}\right)^{\mathrm{a}}$ & notes \\
\hline $\mathrm{H} \cdots \mathrm{Cl}$ & 0.973 & 4.8 & $\mathrm{a}$ \\
$\mathrm{H} \cdots \mathrm{Br}$ & 0.988 & 4.1 & $\mathrm{a}$ \\
$\mathrm{D} \cdots \mathrm{Br}$ & 1.951 & 4.1 & $\mathrm{a}$ \\
$\mathrm{H} \cdots{ }^{16} \mathrm{O}$ & 0.941 & 7.7 & $\mathrm{a}$ \\
$\mathrm{H} \cdots{ }^{18} \mathrm{O}$ & 0.944 & 7.7 & $\mathrm{a}$ \\
$\mathrm{D} \cdots{ }^{16} \mathrm{O}$ & 1.778 & 7.7 & $\mathrm{a}$ \\
$\mathrm{Ti} \cdots{ }^{18} \mathrm{O}_{\mu 2}$ & 13.076 & 6.0 & $\mathrm{~b}$ \\
$\mathrm{Ti} \cdots{ }^{16} \mathrm{O}_{\mu 2}$ & 11.987 & 6.0 & $\mathrm{~b}$ \\
$\mathrm{Ti} \cdots{ }^{18} \mathrm{O}_{\mathrm{t}}$ & 13.076 & 4.8 & $\mathrm{~b}$ \\
$\mathrm{Ti} \cdots{ }^{16} \mathrm{O}_{\mathrm{t}}$ & 11.987 & 4.8 & $\mathrm{~b}$ \\
\hline
\end{tabular}

${ }^{\text {a }}$ Since only the specific values (i.e., $K_{1} / K_{2}$ ) are used to calculate $v_{1} / v_{2}$ in eq 2 , the absolute values of $K$ are not important indeed; we consider that because hydrogen-bonding structures are quite similar for $\mathbf{T i}_{\mathbf{6}} \mathbf{B}$ and $\mathbf{T i}_{\mathbf{6}} \mathbf{C}$, the stretching force constants of $\mathrm{HBr}$ and $\mathrm{HCl}$ obtained in gas phase ${ }^{1,2}$ are used to calculate $v_{1} / v_{2}$. ${ }^{\mathrm{b}}$ estimated from this article according to $v_{\mathrm{Ti}-16 \mathrm{O}_{\mu}}=918$ and $v_{\mathrm{Ti}-16 \mathrm{O}_{\mathrm{t}}}=821 \mathrm{~cm}^{-1}$, respectively.

Table S4. Vibrational band shift calculations ${ }^{\mathrm{a}}$

\begin{tabular}{|c|c|c|c|}
\hline Entry & & experimental data & calculated ratio \\
\hline 1 & $v_{\mathrm{H} \cdots \mathrm{Cl}} / v_{\mathrm{H} \cdots \mathrm{B} r}$ & $\begin{array}{l}706 / 657 \approx 1.08 \\
581 / 549 \approx 1.06\end{array}$ & 1.09 \\
\hline 2 & $v_{\mathrm{H} \cdots \mathrm{B} r}, v_{\mathrm{D} \cdots \mathrm{B} r}$ & $657 / 463 \approx 1.42$ & 1.41 \\
\hline 3 & $v_{{ }^{16} \mathrm{O}_{\mathrm{t}}-\mathrm{H}} / v^{18} \mathrm{O}_{\mathrm{t}}-\mathrm{H}$ & $3143 / 3147 \approx 1$ & 1.00 \\
\hline 4 & $\delta_{16} \mathrm{O}_{\mathrm{t}-\mathrm{H}} / \delta_{{ }^{18} \mathrm{O}_{\mathrm{t}}-\mathrm{H}}$ & $\begin{array}{l}1625 / 1620 \approx 1 \\
1604 / 1600 \approx 1\end{array}$ & 1.00 \\
\hline 5 & $v_{\mathrm{Ti}^{-16} \mathrm{O}_{\mu 2}} / v_{\mathrm{Ti}^{-}{ }^{18} \mathrm{O}_{\mu 2}}$ & $918 / 881 \approx 1.04$ & 1.04 \\
\hline 6 & $\delta_{\mathrm{Ti}^{-16} \mathrm{O}_{\mu}} / \delta_{\mathrm{Ti}^{18}{ }^{18} \mathrm{O}_{\mu}}$ & $395 / 376 \approx 1.05$ (Raman) & 1.04 \\
\hline 7 & $v_{\mathrm{Ti}-{ }^{16} \mathrm{O}_{\mathrm{t}}} / v_{\mathrm{Ti}^{1}{ }^{18} \mathrm{O}_{\mathrm{t}}}$ & $821 / 788 \approx 1.04$ & 1.04 \\
\hline 8 & 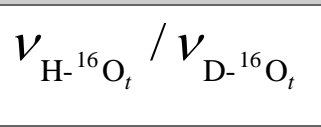 & $\begin{array}{l}3143 / 2348 \approx 1.33 \\
1625 / 1197 \approx 1.36 \\
1604 / 1179 \approx 1.36\end{array}$ & 1.37 \\
\hline
\end{tabular}




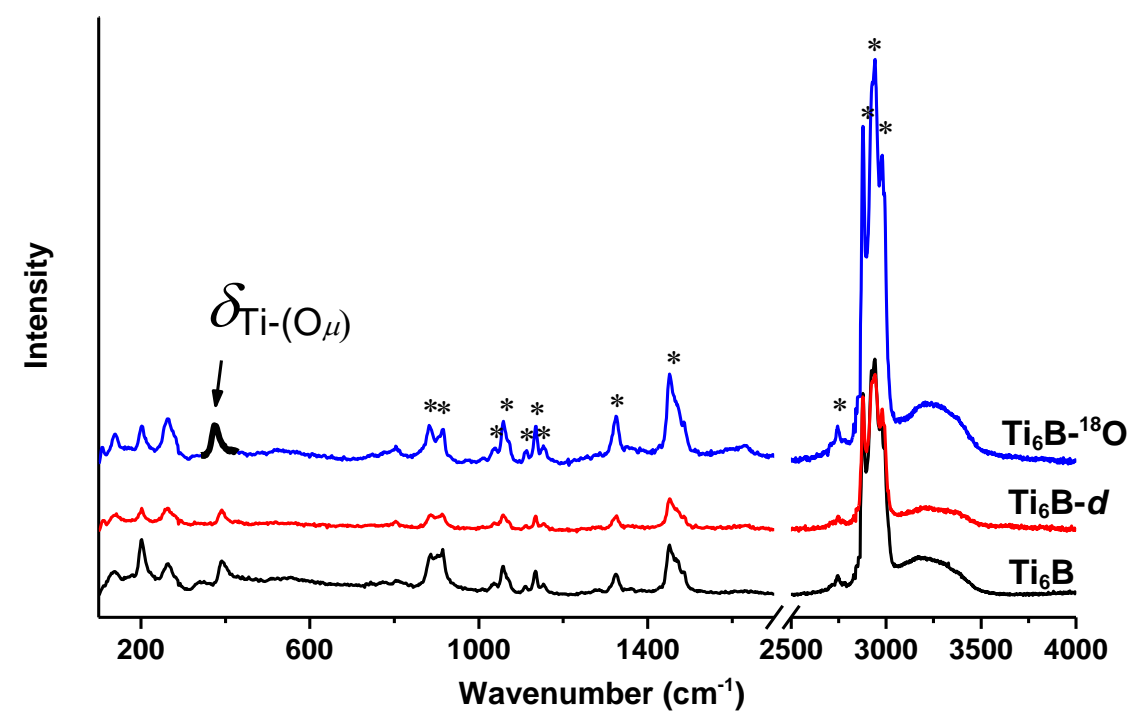

Figure S7. Raman spectra of $\mathbf{T i}_{\mathbf{6}}$ compounds. The peaks labeled with “*” are vibrational modes of TBA cation.

Comparing the Raman spectra of $\mathbf{T i}_{\mathbf{6}} \mathbf{B}$ (s) and TBAB (s), the band centered at $395 \mathrm{~cm}^{-1}$ should be assigned to Ti-O bond. By labeling with ${ }^{18} \mathrm{O}$, this peak is red-shifted to $376 \mathrm{~cm}^{-1}$, consistent with the predicted peak shifts by the Hooke's Law (Table S4). Meanwhile this band is hardly shifted by deuterium labeling, indicating that this $\mathrm{O}$ must not directly bond to $\mathrm{H}$. This and literature results ${ }^{5}$ firmly indicate the $395 \mathrm{~cm}^{-1}$ band should be assigned to a bending mode of Ti- $\left(\mathrm{O}_{\mu}\right)$-Ti. The $910 \mathrm{~cm}^{-1}$ band which is suggested ${ }^{5}$ to be antisymmetric stretches of Ti- $\left(\mathrm{O}_{\mu}\right)$ is hardly visible in the present study.

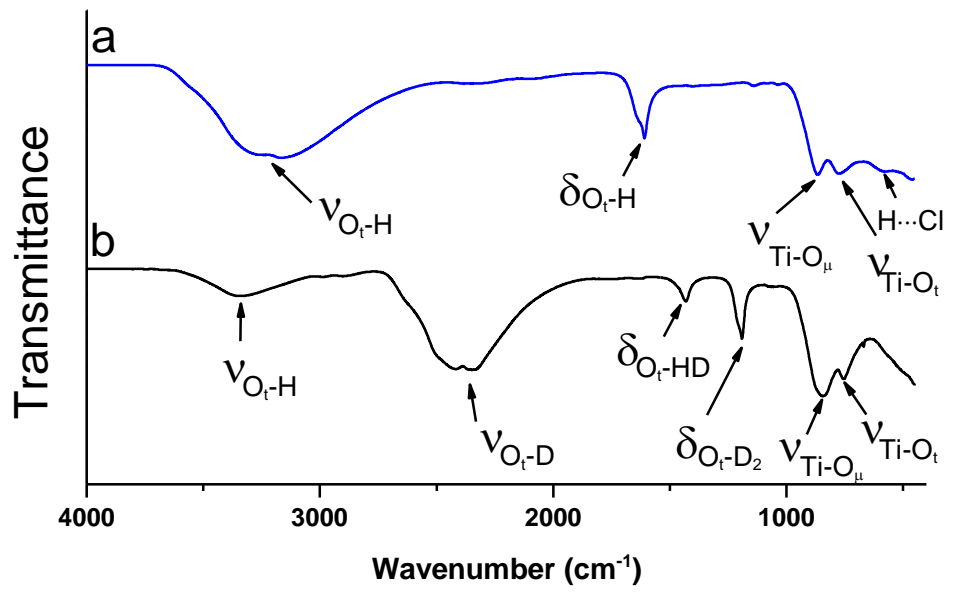

Figure S8. IR spectra of $\mathbf{T i}_{8} \mathbf{C}$ and $\mathbf{T i} \mathbf{i}_{8} \mathbf{C}-d$.

Stretch resonance band of $\mathrm{O}_{t^{-}} \mathrm{H}$ at ca. $3160 \mathrm{~cm}^{-1}$ (wide) is red-shifted to ca. $2350 \mathrm{~cm}^{-1}$ (wide), meanwhile its scission resonance band at $1608 \mathrm{~cm}^{-1}$ is shifted to $1190 \mathrm{~cm}^{-1}$. Both shift are consistent with the expected values due to deuterium substitution (Table S5). Interestingly, the stretch band of Ti$\mathrm{O}_{\mu}$ becomes broader and is red-shifted from 867 to $845 \mathrm{~cm}^{-1}$, indicating D-labeling actually weakens the Ti- $\mathrm{O}_{\mu}$ bond. Some H-contamination in $\mathrm{D}_{2} \mathrm{O}$ used in synthesis of $\mathbf{T} \mathbf{i}_{\mathbf{8}} \mathbf{C}$ - $d$ should exist, as can be inferred from the residue resonance at ca. $3271 \mathrm{~cm}^{-1}$ and a new peak centered at $1432 \mathrm{~cm}^{-1}$ (assigned as $\delta_{O_{t}-H D}$ ). 
Table S5. IR band of $\mathrm{Ti}_{8}$ clusters

\begin{tabular}{|l|l|l|l|l|l|l|}
\hline Entry & & $v_{\mathrm{H} \cdots \mathrm{Ot}}$ & $\delta_{\mathrm{H} \cdots \mathrm{Ot}}$ & $v_{\mathrm{Ti} \cdots} \mu$ & $v_{\mathrm{Ti} \cdots \mathrm{Ot}}$ & $v_{\mathrm{H} \cdots \mathrm{Cl}}$ \\
\hline 1 & $\mathrm{Ti}_{8} \mathrm{C}$ & 3172,3164 & 1608 & 867 & 771 & 579 \\
\hline 2 & $\mathrm{Ti}_{8} \mathrm{C}-d$ & 2420,2344 & 1190 & 845 & 755 & out of range \\
\hline
\end{tabular}

Table S6. Ti 8 's IR band shift due to deuterium-labeling

\begin{tabular}{|l|l|l|l|}
\hline Entry & & experimental data & calculated ratio \\
\hline 1 & $v_{\mathrm{H}^{1{ }^{16} \mathrm{O}}} / v_{\mathrm{D}-{ }^{16 \mathrm{O}}}$ & $3172 / 2420=1.31$ & 1.37 \\
& $\delta_{\mathrm{H}^{1{ }^{16} \mathrm{O}}} / \delta_{\mathrm{D}_{-1}{ }^{16 \mathrm{O}}}$ & $3164 / 2344=1.35$ & \\
\hline 2 & $1608 / 1190=1.35$ & 1.37 \\
\hline
\end{tabular}

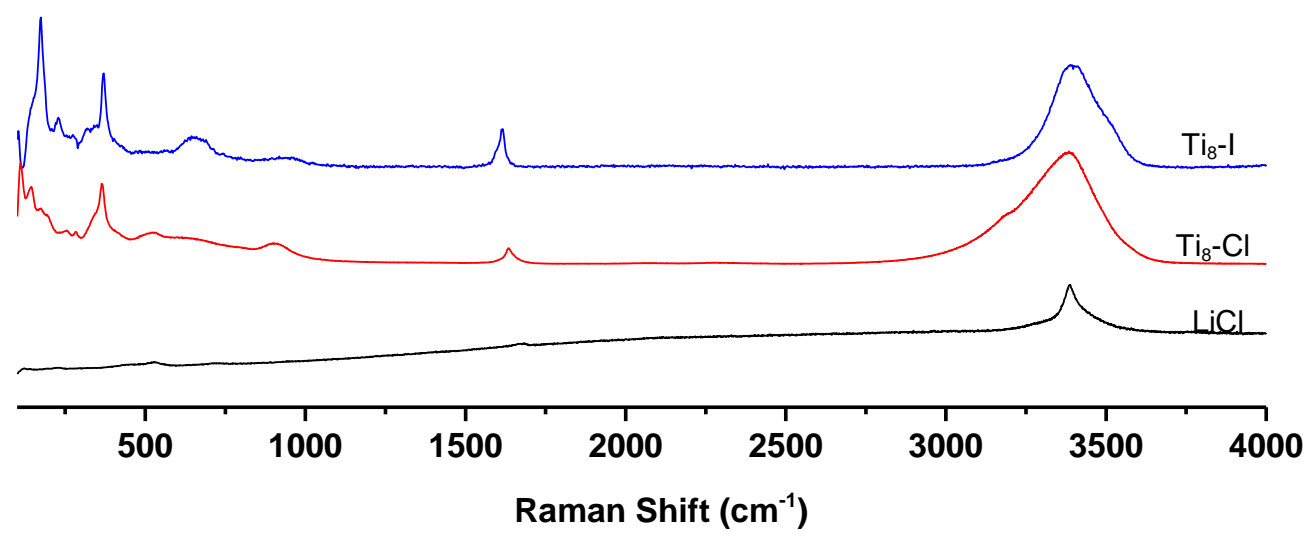

Figure S9. Raman spectra of $\mathbf{T i}_{8}$ compounds.
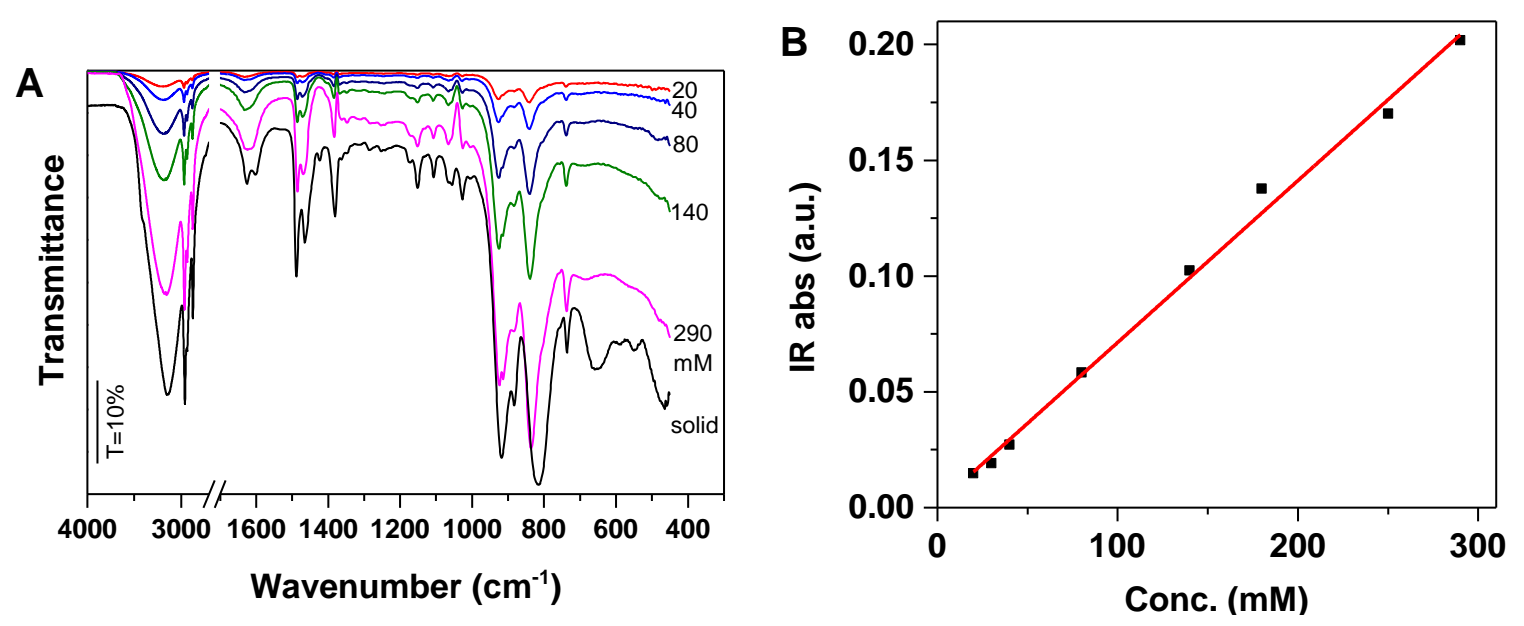

Figure S10. (A) FTIR spectra of solid $\mathbf{T i}_{6} \mathbf{B}$ and acetonitrile solutions of $\mathbf{T i}_{6} \mathbf{B}$ and $(\mathbf{B})$ the absorbance of Ti- $\left(\mathrm{O}_{\mu}\right)$ band $\left(924 \mathrm{~cm}^{-1}\right)$ as functions of $\mathbf{T i}_{\mathbf{6}} \mathbf{B}$ concentration. The red line in panel B is the linear fit with $\mathrm{R}^{2}=0.995$.

Description to Figure S10. As can be seen in Figure S10A, the vibrational frequencies of Ti- $\left(\mathrm{O}_{\mu}\right)$ and Ti- $\left(\mathrm{O}_{t}\right)$ centered at 918 and $821 \mathrm{~cm}^{-1}$ respectively for solid $\mathbf{T} \mathbf{T}_{\mathbf{6}} \mathbf{B}$, are slightly blue-shifted upon solvation in acetonitrile (and meanwhile that of $\mathrm{H} \cdots \mathrm{Br}$ disappears as expected). Besides this, IR spectra of $\mathrm{MeCN}$ solutions of $\mathbf{T i}_{\mathbf{6}} \mathbf{B}$ does not change with concentration (ranging from $20 \mathrm{mM}$ to near saturated, ca. 290 
$\mathrm{mM})$; meanwhile, an analysis of the Ti- $\left(\mathrm{O}_{\mu}\right)$ stretching mode indicates that its IR absorbance follows the Lambert-Beer law as a function of $\mathbf{T i}_{\mathbf{6}} \mathbf{B}$ concentration (Figure S10B). Further, the solutions of various concentrations, fresh and aged for a month, when quickly air-dried, exclusively yielded $\mathbf{T i}_{\mathbf{6}} \mathbf{B}$ without impurities (checked by IR). The above evidences firmly indicate the structural stability of $\mathbf{T i}_{\mathbf{6}}$ in acetonitrile. By contrast, neither $\mathbf{T i}_{\mathbf{8}} \mathbf{I}$ nor $\mathbf{T} \mathbf{T i}_{\mathbf{8}} \mathbf{C}$ is soluble in acetonitrile. Using the same criteria as above, we found out that structure of $\mathbf{T i}_{\mathbf{6}}$ clusters remain intact in other solvents like THF and nitromethane as well. However, although $\mathbf{T} \mathbf{T i}_{\mathbf{6}}$ is soluble, the characteristic vibration modes of $\mathrm{Ti}-\left(\mathrm{O}_{\mu}\right)$ and $\mathrm{Ti}-\left(\mathrm{O}_{t}\right)$ disappear upon dissolution in water and methanol, indicating disruption of the cluster structure.

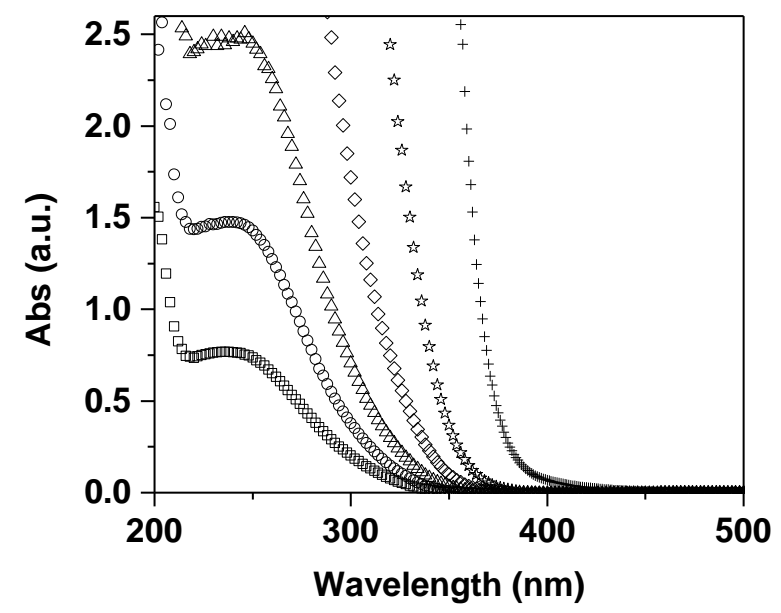

Figure S11. UV-vis electron absorption spectra of $\mathbf{T i}_{\mathbf{6}} \mathbf{C}$ in acetonitrile at the following concentration: $1.7 \times 10^{-5}, 3.4 \times 10^{-5}, 5.9 \times 10^{-5}, 1.5 \times 10^{-4}, 4.5 \times 10^{-4}$, and $5 \times 10^{-3} \mathrm{M}$, respectively.

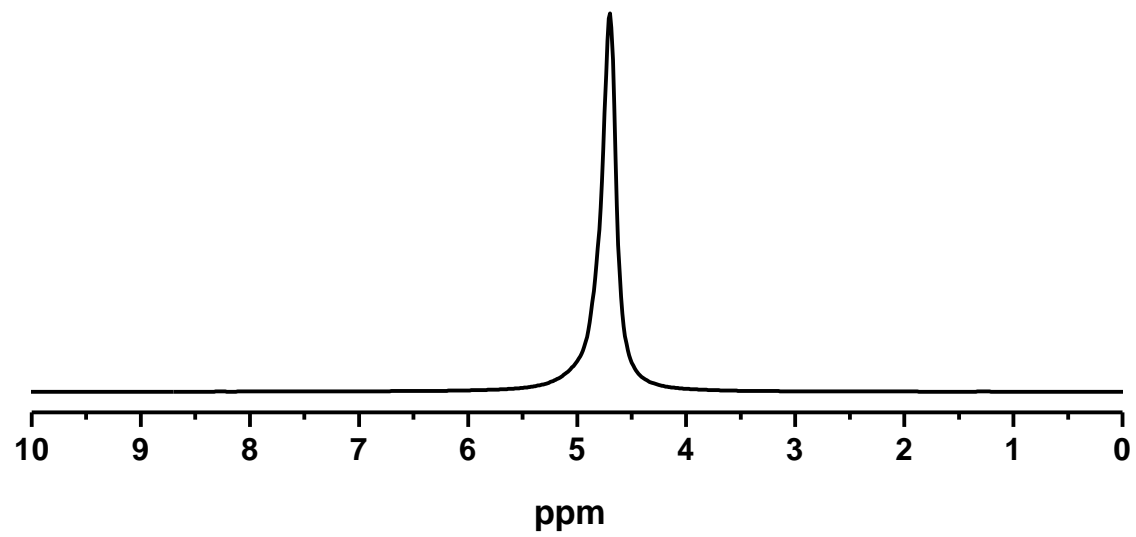

Figure S12. ${ }^{1} \mathrm{H}$ MAS NMR of $\mathbf{T i} \mathbf{C}$. 


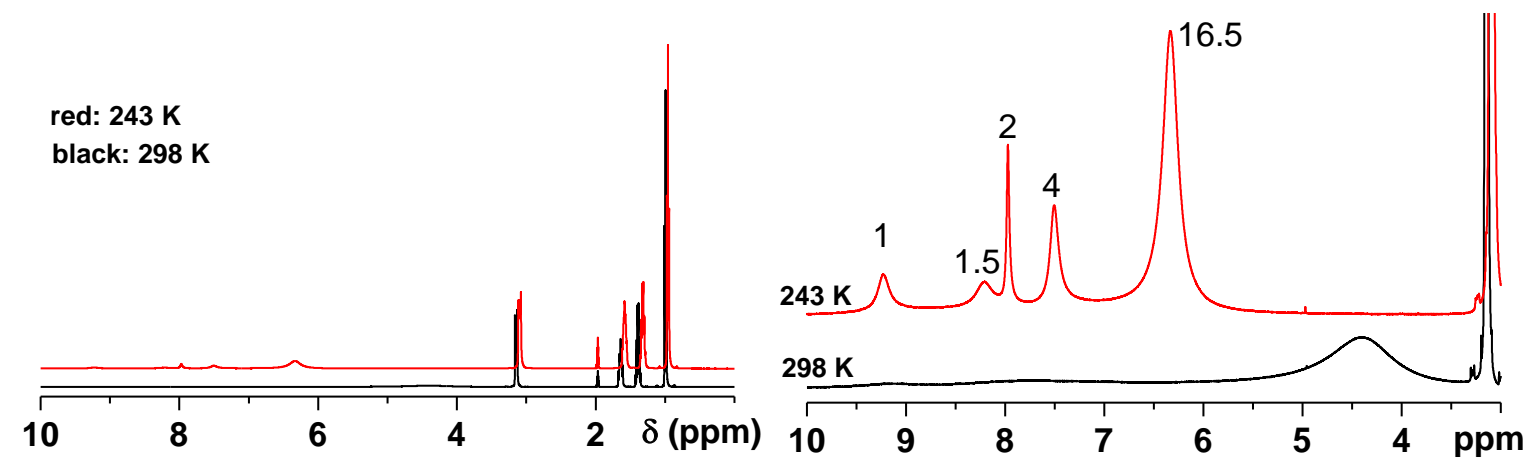

Figure S13. ${ }^{1} \mathrm{H}$ NMR spectra of $\mathbf{T i}_{6} \mathbf{C}\left(80 \mathrm{~g} \mathrm{~L}^{-1}\right)$ in acetonitrile at 25 and $-40{ }^{\circ} \mathrm{C}$. The right panel is an enlarged view of the left. Note that the relative area of the peaks are labeled, although to elucidate the peak assignments was not successful.
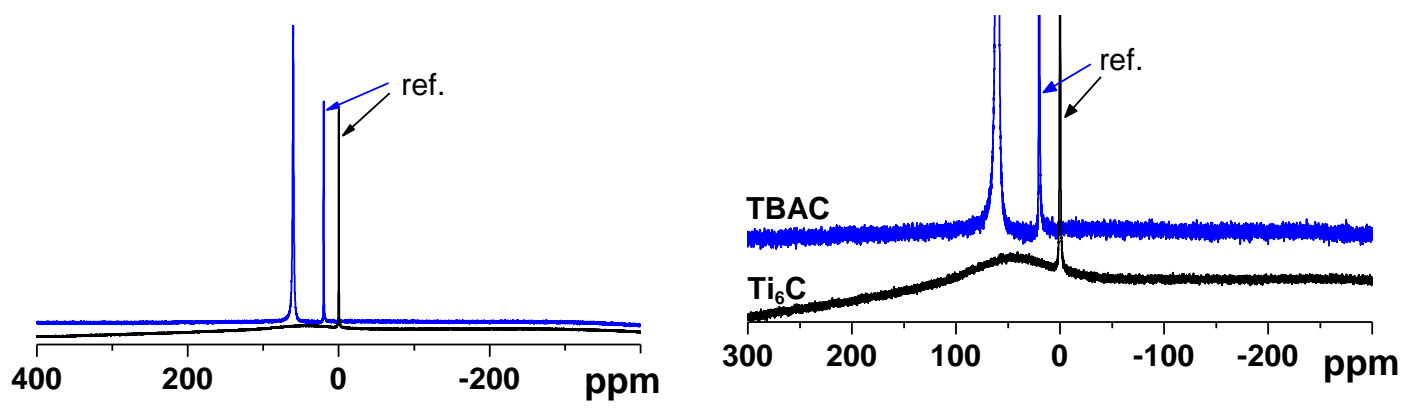

Figure S14. ${ }^{35} \mathrm{Cl}$ NMR of $\mathbf{T i}_{6} \mathbf{C}(0.10 \mathrm{M}$; black) and TBAC (1.4 M; blue) in acetonitrile solutions. The right panel is an enlarged view of the left. $2.0 \mathrm{M} \mathrm{LiCl}$ in $\mathrm{D}_{2} \mathrm{O}$ was used as the reference (in an NMR coaxial insert).

Optimization of the cluster structures using DFT method. The structural optimization was carried out on a cluster with initial structure obtained from the single crystal, keeping the halide anions and removing the TBA cations. During the optimization, the position of halide anions were fixed, and the position of other atoms $(\mathrm{H}, \mathrm{O}$ and $\mathrm{Ti})$ were relaxed without any constraint. To reveal the role of halide anions, the initial cluster without halide anions was optimized at the same theory level.

For structural optimization, the Gaussian09 with the B3LYP functional and the Lanl2dz basis set was applied.

We found out that optimization of the clusters' $\left(\left[\mathrm{Ti}_{6} \mathrm{O}_{8}\left(\mathrm{OH}_{2}\right)_{20}\right]^{8+}\right.$ and $\left.\left[\mathrm{Ti}_{8} \mathrm{O}_{12}\left(\mathrm{OH}_{2}\right)_{24}\right]^{8+}\right)$ structures without counter anions always failed, giving results showing aqua ligands dissociated from the cluster surfaces (Figure S16). Only with the halide anions included and location fixed, can the aqua ligands be stabilized and the optimization be successfully carried out. The DFT optimization gives more logical locations of $\mathrm{H}$-atoms of aqua ligands (all $\mathrm{O}-\mathrm{H}$ bonds are anchored to the halide anions) than added by Olex 1.2 software, as shown below (Figure S15): 

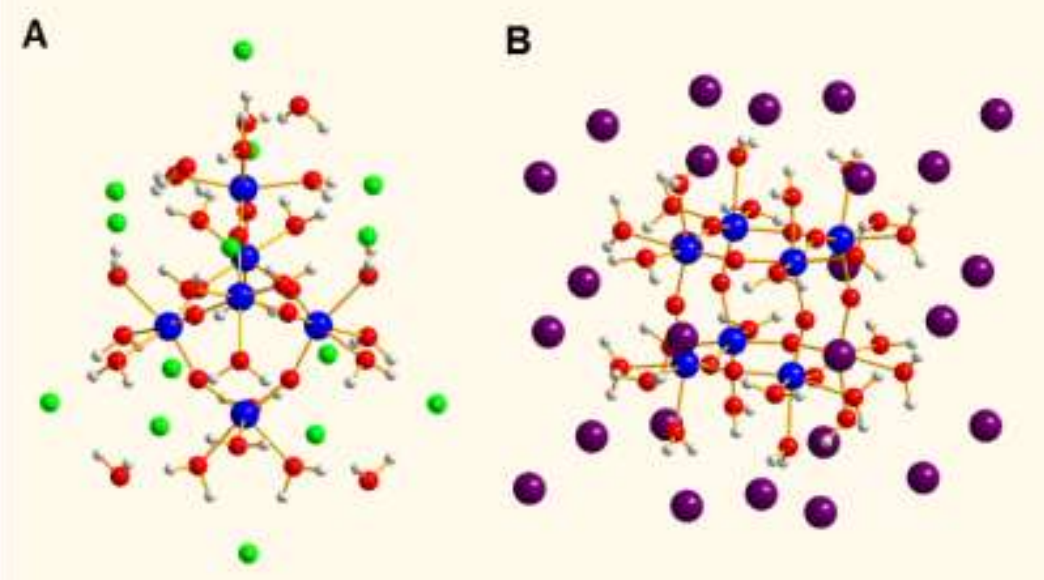

Figure S15. Optimized $\mathbf{T i} \mathbf{6}_{\mathbf{6}}$ (left) and $\mathbf{T i} \mathbf{i}_{\mathbf{8}}$ (right) cluster structures using DFT method.

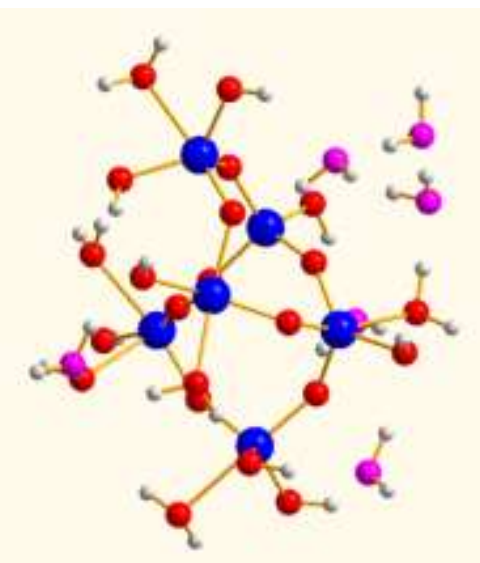

Figure S16. Optimized $\mathbf{T i}_{\mathbf{6}}$ cluster structure using DFT method. Without the counter anions, some aqua ligand (highlighted in purple) would become labile and dissociate from the cluster.

\section{References}

(1) Polavarapu, P. L. Vibrational Spectra: Principles and Applications with Emphasis on Optical Activity: Principles and Applications with Emphasis on Optical Activity; Elsevier, 1998.

(2) Jr. Wilson, E. B.; Decius, J. C.; Cross, P. C. Molecular Vibrations: The Theory of Infrared and Raman Vibrational Spectra; Dover Publications, 1980.

(3) Thornton, S. T.; Rex, A. In Modern Physics for Scientists and Engineers; Cengage Learning: Boston, 2013, p 339-385.

(4) Barrow, G. M. The Structure of Molecules; New York: Benjamin, 1963.

(5) Reichmann, M. G.; Bell, A. T. Langmuir 1987, 3, 111-116. 